\title{
UN ANTIJESUITA EN LA MITRA DE MANILA: BASILIO SANCHO DE SANTA JUSTA Y RUFINA
}

\author{
Santiago LORENZO GARCÍA \\ Universidad de Alicante
}

\begin{abstract}
Resumen
Basilio Sancho encontró durante su pontificado en la diócesis de Manila (1767-1787) múltiples dificultades. En los primeros años, entre 1767 y 1770, el Metropolitano se enfrentó a los Provinciales de las distintas religiones con motivo de la visita pastoral, procuró acelerar al máximo la expulsión de los jesuitas isleños, hacia los que sentía gran aversión, y se opuso abiertamente al gobernador Raón y al comisionado Basaraz, a quienes acusó de negligentes en su labor política. En el año 1770, el extrañamiento de la Compañía de Jesús en enero, la llegada a Manila en julio del nuevo gobernador Simón de Anda -al igual que don Basilio inflexible regalista-, y la caída en desgracia de Raón y Basaraz en septiembre ofrecieron un breve, pero reparador respiro, al enérgico y firme Prelado.
\end{abstract}

\begin{abstract}
Basilio Sancho experienced many difficulties during his reign in the diocese of Manila (1767-1787). In the first years, between 1767 and 1770, the Metropolitan was opposed the Provincial of the different religions because of the pastoral visit, he tried hard to accelerate the expulsion of the islander Jesuits, toward which he felt great distaste, and was openly opposed to the governor Raón and to the commissioner Basaraz, who were accused of negligence in their political labor. In the year 1770, the expulsion of the Company of Jesus in January, the arrival in Manila in July of the new governor Simón de Anda -an inflexible defensor of the royal prerogatives like Basilio-, and the fall from grace of Raón and Basaraz in September, offered a short but beneficial pause to the energetic and firm Prelate.
\end{abstract}

La expulsión de los jesuitas de Filipinas favoreció el recrudecimiento de disputas que, desde hacía tiempo, se estaban fraguando dentro de las esferas del poder civil y eclesiástico en aquella lejana provincia ${ }^{3}$. Uno de los protagonistas más activos en estas luchas fue el Metropólitano de Manila Basilio Sancho de Santa Justa y Rufina

1. Ver LORENZO GARCÍA, Santiago, La expulsión de los jesuitas filipinos: un ejemplo de disputa por el poder político, Revista de Historia Moderna, Núm. 15, Universidad de Alicante, 1996. 
(1767-1787). Este artículo pretende analizar el papel que jugó este personaje en los sucesos que rodearon el extrañamiento de la Compañía de Jesús del archipiélago, lo cual nos permitirá, igualmente, mostrar su perfil ideológico, marcado por su celo regalista, su profundo antijesuitismo y su oposición ferviente a algunos representantes del poder político isleño, condescendientes con los jesuitas.

Natural de Villanueva del Rebollar (Teruel), Sancho nació el 17 de septiembre de 1728. Ingresó en el Colegio calasancio de Peralta de la Sal el 15 de diciembre de 1743, para estudiar más tarde teología en Daroca y Zaragoza, donde fue ordenado sacerdote. Enseñó esta disciplina en Valencia y ocupó pronto el cargo de secretario provincial de la orden de las Escuelas Pías, ascendiendo rápidamente al de Procurador General de la Provincia de Aragón en la Corte en el año 1762. Su carrera fue vertiginosa; al poco tiempo, fue nombrado examinador y consultor regio, y en 1764 predicador real, teólogo y calificador del Santo Oficio, así como consejero del Infante Felipe, duque de Parma y hermano de Carlos III. Su fama creció y el Rey lo propuso para la Mitra de Manila en diciembre de 1765; el Papa Clemente XIII lo preconizó en abril de 1766, y fue consagrado ese mismo año en la Iglesia de San Francisco de los Mercedarios de Madrid por Manuel Quintano Bonifaz, Arzobispo titular de Pharsalus (Farsalo) e Inquisidor General. Salió del Puerto de Cádiz rumbo a su nuevo destino el 9 de febrero de 1767, arribando el 17 de julio de ese mismo año ${ }^{2}$.

Antes de partir para la Sede de Manila parece que don Basilio ya se había mostrado partidario ante el Soberano y sus ministros de la expulsión ${ }^{3}$, lo que le valió rápidamente que sus enemigos lo tacharan de «jansenista», acusación que mantuvo más tarde Menéndez y Pelayo ${ }^{4}$. A su llegada a Filipinas, un acontecimiento acrecentó sus recelos respecto a los jesuitas y al clero regular en general, hasta el punto de convertirlos en enconada ojeriza. Fueron sentimientos recíprocos. Cuando a los pocos días de desembarcar en su diócesis el Prelado hizo pública su intención de realizar la visita pastoral en su arzobispado, las religiones mostraron, al unísono, su desacuerdo más rotundo. Era un asunto que arrancaba de largo; se había planteado ya en tiempos del primer Obispo de Filipinas fray Domingo de Salazar, en el último tercio del siglo XVI; pero su intento y los posteriores de otros obispos como Millán Poblete (16531672) o Diego Camacho y Ávila (1697-1706) chocaron con la fuerza de los regulares, que se escudaban en la escasez del clero secular para mantener su independencia ${ }^{5}$. La resistencia de las órdenes encolerizó a Basilio Sancho, quien, desde el comienzo de su pontificado, tuvo como un objetivo básico el fortalecimiento de la jurisdicción episcopal frente a aquéllas. Para ello, se entregó a una ardua tarea de preparación y

2. Estos datos biográficos han sido obtenidos de los trabajos de MANCHADO LÓPEZ, M., Conflictos Iglesia-Estado en el Extremo Oriente Ibérico. Filipinas (1767-1787). Universidad de Murcia, 1994; y GUITARTE IZQUIERDO, Vidal, Episcopologio español (1700-1867). Españoles obispos en España, América, Filipinas y otros paises, Publicaciones del Instituto Español de Historia Esclesiástica, Subsidia núm. 29, Roma, 1992.

3. EGIDO, Teófanes, La expulsión de los jesuitas de España, en Historia de la Iglesia en España. La Iglesia en la España de los siglos XVII y XVIII, Vol. IV, Biblioteca de Autores Cristianos, Madrid, 1979, p. 772.

4. MENÉNDEZ Y PELAYO, Marcelino, Historia de los heterodoxos españoles. Protestantismo y sectas misticas. Regalismo y Enciclopedia. Heterodoxia en el Siglo XIX, Vol. II, Biblioteca de Autores Cristianos, Madrid, 1956, p. 499

5. GUTIÉRREZ, L., Historia de la Iglesia en Filipinas (1565-1900), Mapfre, Madrid, 1992, pp. 210-211. 
formación de curas seculares nativos para sustituir a los regulares en las parroquias de la diócesis ${ }^{6}$. Se trataba de una declaración de guerra sin cuartel a las corporaciones religiosas filipinas. Las hostilidades estuvieron marcadas por la oposición sistemática de estas últimas a los dictados del Arzobispo; por la adopción de medidas drásticas en su contra, como la violenta expulsión de los agustinos calzados de treinta parroquias de Papamga, una de las regiones más ricas del archipiélago; y por la dificultad de contar con un clero secular apropiado en número y calidad para cubrir las vacantes?

El primer encontronazo grave con un representante del clero regular se produjo en enero de 1768, precisamente con el P. José de Torres, Provincial de los jesuitas, el cual se negó rotundamente a que el Ordinario iniciase la visita pastoral en las parroquias dirigidas por sus religiosos ${ }^{8}$. A partir de este momento, los ataques lanzados contra la Compañía de Jesús desde la Mitra manilense fueron constantes y cada vez más demoledores. La llegada a las islas del Real Decreto de expulsión el 17 de mayo de ese año ${ }^{y}$ allanó el camino y el Arzobispo vio la hora de apuntillar a uno de sus enemigos más peligrosos. No perdió el tiempo. Cinco días después, hizo público un Edicto en que, aprovechando el difícil trance por el que atravesaba la Sociedad jesuítica, hacía suyas tesis muy del gusto del gobierno de Madrid. El «obispo funcionario» al servicio de la Corona, portavoz y apologeta de los derechos del Soberano y de la legitimidad de sus regalías, emergía con fuerza inusitada:

«Y por lo tanto mandamos en virtud de santa obediencia a todos los predicadores $y$ demás personas eclesiásticas, nuestros súbditos que en el púlpito confesionario y en conversaciones particulares inculquen, fomenten, promuevan la obligación que a todos incumbe de respetar, obedecer y venerar como fieles y leales vasallos las determinaciones de Su Majestad, huyendo como de blasfemia la necísima presunción de querer reducir a problemas las justísimas providencias del Monarca, que deben siempre recibirse y adorarse como emanadas de las incomprehensibles disposiciones del todo poderoso» ${ }^{10}$.

El documento parece que provocó reacciones airadas entre los jesuitas filipinos, ya que en él, además, se arremetía violentamente contra la moral ignaciana. Según los testimonios de Sancho, se produjo un auténtico torrente de pasquines ofensivos contra su persona, que nacían del Colegio Máximo de San Ignacio de Manila, donde se hallaban concentrados los regulares de la capital ${ }^{11}$. Las protestas elevadas por don Basilio sobre estas cuestiones al gobierno político de las islas no fueron, en su opinión, atendidas convenientemente, y pronto surgieron roces entre ambas partes. El Arzobis-

6. Ibidem, p. 212.

7. Más información sobre estas cuestiones en RODRÍGUEZ, Isacio, Filipinas: La organización de la Iglesia y ABAD, Antolín, Filipinas: Labor misional y pastoral, en Historia de la Iglesia en Hispanoamérica y Filipinas (siglos XV-XIX), vol. II: Aspectos regionales, B.A.C., Madrid, 1992; y en los trabajos de MANCHADO LÓPEZ, M. y GUTIÉRREZ, Lucio, citados en notas precedentes.

8. MANCHADO LÓPEZ, M., La Compañía de Jesús y la Visita diocesana en Filipinas. Los meses previos a la expulsión, en Actas del Congreso «La Compañia de Jesús en América: Evangelización y justicia. Siglos XVII y XVIIl», Córdoba, 1993, p. 175.

9. DE LA COSTA, H., The Jesuits in the Philippines (1581-1767), Harvard University Press, Cambridge-Massachusetts, p. 583.

10. A.H.N., Clero, Jesuitas, leg. 239: Edicto del Arzobispo de Manila Basilio Sancho, Manila, 22 de mayo de 1768.

11. A.H.N., Clero, Jesuitas, leg. 239: Carta del Arzobispo de Manila Basilio Sancho al Conde de Aranda, Manila, 27 de diciembre de 1770 . 
po siempre se quejó de la excesiva condescendencia que desde la Real Audiencia de Manila se tenía con los padres de la Compañía, su doctrina e ideas. El asunto de la expulsión práctica de los regulares del archipiélago caldeó todavía más el ambiente.

El gobernador José Raón, de conformidad con el oidor Manuel Galbán, juez comisionado para el negocio de los jesuitas, había decidido expatriar un primer contingente de 64 regulares ese mismo verano por la vía de Nueva España. Salieron de puerto el 1 de agosto, aunque una fuerte tormenta a principios de septiembre obligó al capitán de la nave a volver a Filipinas, con dos bajas entre los religiosos, una de ellas la del Padre Provincial Juan Silverio Prieto. Los días 25 y 26 de octubre fueron ingresados de nuevo en el Colegio Máximo, teniendo que esperar los regulares hasta el verano del año siguiente para ser embarcados nuevamente, por ser entonces los vientos favorables para la navegación ${ }^{12}$. Esta demora forzosa alarmó al Prelado por «los inconvenientes que en estas islas puede causar la retardación de estos enemigos del género humano», y fue achacada a la negligencia con que había actuado Raón en la operación, quedando libre de culpa el diligente comisionado Galbán:

«ha trabajado (Galbán) y trabaja como buen ministro; los autos impondrán a V. E. de su tesón y negligencias del gobernador ${ }^{13}$.

La presencia de los jesuitas en el archipiélago parece haberse hecho insoportable para el Metropolitano durante el año 1769:

"Con la arribada de la fragata San Carlos que conducía al puerto de Acapulco los principales mandarines jesuitas se nos volvieron a entrar por las puertas de Manila y con ellos una guerra que en todo el año 69 no se ha visto el Arzobispo libre de confusiones y trabajo» ${ }^{14}$.

En ese año, además, las relaciones entre el Arzobispado y el gobierno de Manila no hicieron sino empeorar. Un acontecimiento contribuyó especialmente en este sentido. A finales del verano, el navío «Venus» arribó al Puerto de Cavite con varios escritos a bordo en los que se criticaba duramente la doctrina jesuítica ${ }^{15}$. La respuesta

12. LORENZO GARCíA, Santiago, La expulsión de los jesuitas de la Provincia de Filipinas, en Actas de la IV Reunión Científica de la Asociación Española de Historia Moderna, Alicante, 1996.

13. A.H.N., Clero, Jesuitas, leg. 239: Carta del Arzobispo de Manila Basilio Sancho al Conde de Aranda, Manila, 20 de noviembre de 1768 .

14. A.H.N., Clero, Jesuitas, leg.239: Carta del Arzobispo Basilio Sancho al Rey, Manila, 1 de enero de 1770 .

15. Gracias a un certificado de Fray Pedro Miguel Díez, del Sagrado Orden de Predicadores y Notario del Santo Oficio conocemos los títulos de estos libros: El primero tiene como autor a Tomás de Angulo y su título reza como sigue «Instrucción a los príncipes sobre la política de los padres jesuitas, ilustrada con largas notas y traducida del italiano en portugués y ahora en castellano con el suplemento de la religión ortodoxa de los jesuitas», con Superior Permiso, Imprenta de Pantaleón Aznar, Calle del Arenal, Casa del Excelentísimo Señor Duque de Arcos, Madrid, 1768; «se hallará en la librería de José Batanero». Del mismo Tomás de Angulo: «Reflexiones sobre el Memorial presentado a la Santidad de Clemente Trece por el General de los jesuitas en que se refieren varios hechos de los superiores y misioneros de esta orden en todas las partes del mundo, dirigidos a frustrar las resoluciones de los Papas contra sus procedimientos y doctrinas y que demuestran la incorregibilidad absoluta de este cuerpo», traducción del italiano. Madrid, 1768, «se hallará en casa de Francisco Fernández, frente a las gradas de San Felipe el Real». El tercero, escrito por el Doctor Neyra: «Retrato de los jesuitas formado al natural por los más sabios y más ilustres católicos. Juicio hecho de los jesuitas autorizado con auténticos e innegables testimonios por los mayores y más esclarecidos hombres de la Iglesia y 
de los partidarios de la Compañía y de sus enemigos fue inmediata, sobre todo cuando el oidor Juan Domingo Blas de Basaraz, nuevo comisionado para el asunto de la expulsión ${ }^{16}$, dictó orden de confiscar los libros, negando con ello explícitamente la difusión de sus contenidos en el archipiélago. El comisionado apoyaba su proceder en las instrucciones recogidas en el artículo XVI de la «Pragmática Sanción»:

«Prohibo expresamente que nadie pueda escribir, declarar o conmover, con pretexto de estas providencias, en pro ni en contra de ellas; antes, impongo silencio en esta materia a todos mis vasallos, y mando que a los contraventores se les castigue como a reos de lesa Majestad» ${ }^{17}$.

Basaraz se convirtió, junto a los jesuitas, en blanco de los ataques del Ordinario. En carta de 15 de octubre dirigida al gobernador, protestaba agriamente por la actuación del comisionado, pues los escritos contaban con «Superior permiso» y en Madrid circulaban sin ninguna dificultad:

"Es pues asi que de Madrid han salido dichos papeles. Alli se han impreso y publicado y alli mismo se venden públicamente, donde está de asiento el Monarca, donde el Excelentísimo Señor Presidente y Comisionado por Su Majestad para la obra de la expulsión de los jesuitas de uno y otro mundo, donde los Supremos Consejos y demás celosos Ministros de Su Majestad, quienes ciertamente se hallan instruidos de su Real Mente, y de la sabia y sana intención de la Pragmática Sanción, finalmente, donde con más eficacia, celo y amor del Real Servicio le llevan a debido efecto las soberanas leyes. Alli, alli, lejos de prohibirse estos papeles se aprueban, se dan al público, se expenden y en los Mercurios se da aviso a todos, donde se venden; pero en Manila, donde su noticia y lectura es aún más necesaria para la instrucción y desengaño de estos pobres ciegos; aqui, sin orden, sin comisión, sin facultad que resida por ninguna vía en el Ministro, que to ha ejecutado se prohibe el que corran, se recogen y quitan de un extraño modo de las manos de las gentes con desdoro del Superior Permiso...» ${ }^{18}$.

del Estado, desde el año de mil quinientos cuarenta en que fue su fundación hasta el de mil seiscientos cincuenta», traducido del portugués al castellano, tercera impresión con Superior Permiso, Oficina de la viuda de Eliseo Sánchez, Madrid, 1768. Y el último es también del Doctor Neyra y su título: «Continuación del retrato de los jesuitas, formado al natural por los más sabios y más ilustres católicos», tercera impresión con Superior Permiso, Oficina de la viuda de Eliseo Sánchez, Madrid, 1768.

Según Francisco Aguilar Piñal estas dos últimas obras son de Francisco Mariano Nifo y Cagigal, que habría empleado el pseudónimo de «doctor Neyra». En Bibliografía de autores españoles del siglo XVIII, Tomo VI (N-Q), CSIC, Madrid, 1991, pp. 80-81.

A.H.N., Clero, Jesuitas, leg. 239: Certificado del Notario del Santo Oficio Fray Pedro Miguel Díez, Manila, 25 de noviembre de 1769 .

16. Su antecesor Manuel Galbán falleció el 31 de mayo de 1769 tras una larga enfermedad; al día siguiente, el gobernador Raón nombró comisionado para el negocio de los jesuitas al oidor Juan Domingo Blas de Basaraz. A.H.N., Clero, Jesuitas, leg. 239: "Testimonio de las primeras diligencias de la comisión conferidas al Sr. Don Domingo Blas de Basaraz, oidor decano de esta Real Audiencia para que siga con la ejecución del Real Decreto de extrañamiento de los regulares de la Compañia y ocupación de sus temporalidades por muerte del Señor D. Manuel Galbán y Ventura», Manila, 1 de junio de 1769.

17. «Pragnática Sanción de Su Majestad, en fuerza de Ley, para el extrañamiento de estos reinos a los regulares de la Compañía, ocupación de sus temporalidades y prohibición de su restablecimiento en tiempo alguno, con las demás precauciones que expresa». EGIDO, T., La expulsión de los jesuitas de España, en Historia de la Iglesia en España. La Iglesia en la España de los siglos XVII y XVIII, Vol, IV, Biblioteca de Autores Cristianos, Madrid, 1979, p. 815.

18. A.H.N., Clero, Jesuitas, Leg. 239: Carta del Arzobispo de Manila Basilio Sancho al gobernador José Raón, Manila, 15 de octubre de 1769. 
Se dudaba, por tanto, de la legalidad que asistîa al ministro para actuar de ese modo, ya que "para haber procedido de la manera dicha el referido oidor en virtud de las citadas claúsulas era preciso se hallase asistido de facultad competente. Mas, por una parte nos consta, por significación de $V$. S. que su comisión no se extiende a tanto [...]. Luego se infiere haber obrado de propio arbitrio, sin comisión del Superior Gobierno de V. S., sin las facultades de comisario de Santo Oficio y sin la autoridad de Inquisidor Ordinario, que en Nos reside»" ${ }^{19}$.

En el mismo escrito se afirmaba, asimismo, que no era la primera vez que se censuraban textos de forma injustificada en esa provincia, pues ya había sucedido algo similar con el «Memorial ajustado del negocio de Barrachán», en relación a la participación de los jesuitas en el Motín de Esquilache; con la Pastoral del Arzobispo de Burgos Rodríguez de Arellano (uno de los ataques más furibundos contra los jesuitas existentes en la literatura del XVIII) ${ }^{20}$; y -lo que resultaba más indignante-con las Cartas del Obispo Juan de Palafox y Mendoza, quien «vive y vivirá en el corazón de todos los buenos vasallos de nuestro Rey y Señor por ambos mundos, porque en uno y otro fue siervo fiel del Señor del Universo, y también fiel y celoso Ministro de la causa y honor de su Soberano, y lumbrera resplandeciente de la Iglesia, cuyas luces preservarán para beneficio común por perpetuas eternidades en sus grandes y famosas obras»".

De estas palabras se desprende que Basilio Sancho compartía la admiración de Carlos III por el que fue Obispo de Puebla de los Ángeles entre 1640 y 1648, y, más tarde, de Osma entre 1654 y 1659. El Monarca fue, además, uno de los grandes promotores de su canonización y auspició la publicación en 1762 de sus obras completas. A las dos cosas - a la publicación y a su canonización-se opusieron abiertamente los jesuitas, que vieron en las ideas del Prelado y en su política práctica, sobre todo en la diócesis de Nueva España, una amenaza y un peligro constantes. La canonización no ha prosperado hasta la fecha y en ello ha influido a buen seguro «la inaudita persecución satírica que soportó el virrey y el obispo Palafox en vida y después de muerto». En Méjico, Palafox chocó no sólo con la Compañía de Jesús; también tuvo que bregar con dominicos, agustinos y franciscanos por asuntos de doctrina, de diezmos y de licencias ministeriales, además de mantener frecuentes encontronazos con dos virreyes: el duque de Escalona y el conde de Salvatierra.

Al encontrar en Filipinas un acogida tan poco favorable por parte del clero regular, don Basilio debió sentirse identificado con el Obispo de Puebla de los Ángeles, con quien compartía, desde luego, su ideario «regalista» y antijesuita ${ }^{22}$.

19. Ibiden.

20. En la Pastoral citada se dicen cosas como ésta sobre los jesuitas: «De estas gentes nos libró su providencia. La quietud con que salieron, las disposiciones, que a este efecto se tomaron, y el sosiego universal, que se logra desde entonces, todo conspira a hacer creer, que echó Dios a esta grande obra su santa bendición. Tened mucha lástima a los que en su ausencia lloran tristes, persuadidos a que es pérdida irreparable, y perdonemos todos la injuria, que se hace en los desahogos de su dolor a todo el estado Eclesiástico, Secular y Regular. No es menester que salgais de vuestras casas para conocer lo enorme de esta injusticia. Ya ha diez y siete meses que se fueron: ¿se conoce acaso en algo, que faltaron?\%. B.N., 3/10072: Rodríguez de Arellano, Pastoral, Madrid, 2 de septiembre de 1768, p. 405.

21. A.H.N., Clero, Jesuitas, Leg. 239: Carta del Arzobispo de Manila Basilio Sancho al gobernador José Raón, Manila, 15 de octubre de 1769.

22. Abundante información sobre el Obispo Juan de Palafox y Mendoza se encuentra en el excelente trabajo de BARTOLOMÉ MARTÍNEZ, G., Jaque mate al obispo virrey. Siglo y medio de sátiras y libelos contra don Juan de Palafox y Mendoza, F.C.E., Madrid, 1991. 
La confiscación de los escritos decretada por el comisionado Basaraz fue suficiente como para considerarlo abiertamente defensor de la causa jesuítica:

"Y asi aún los tenemos dentro de casa y son padres que han engendrado aqui con su doctrina muchísimos hijos. ¿Qué días tan alegres no habrá dado a estos enamorados hijos de aquellos padres el ministro (Basaraz) que recogió los impresos dichos, por donde consta lo honrados que han sido?" ${ }^{23}$.

Ciertamente, parece que el ministro fue muy bien considerado entre los padres de la Compañía, como se desprende de varios testimonios del Diario del jesuita Francisco Javier Puig, quien escribe que Basaraz se portó con ellos de un modo exquisito a la hora de realizar los preparativos para su embarque:

"El 31 de mayo murió de repente el señor Oidor Don Manuel Galbán, que [era] el subdelegado Juez Executor de nuestra expulsión; y luego a 1 de junio señaló el señor Gobernador por sucesor suyo en el oficio al Doctor Don Juan Domingo Blas de Bassaraz, Oidor también de la real Audiencia de Manila y viscaíno de nación, quien se portó con nosotros con quanta benignidad le permitían las órdenes del Rey y las instrucciones del Señor Conde de Aranda».

«Nos alojó (Basaraz) en nuestro Colegio y nos trató con toda atención. Y aunque estuvinos con guardia de soldados por ser formalidad inexcusable, el trato fue verdaderamente digno de su noble corazón y christiano».

«Día 3 a las diez de la mañana nos vino a acompañar en persona hasta la nave, y nos colocó en un puesto de los más cómodos, quanto permitía la estrechez de la nave y la multitud de pasajeros que avía en ella. A las benéficas y pias providencias de este caballero debimos después de Dios el que muchos de nosotros no muriéramos en el viaje tan largo como íbamos a emprender llevados presos en calidad de reos de Estado» ${ }^{24}$.

Su moral y buenas costumbres también fueron puestas en tela de juicio por el Prelado, sobre todo por lo que tocaba a su supuesta escandalosa conducta con las mujeres:

«.... teniendo noticia que vuestro oidor Don Domingo Blas de Basaraz vivía escandalosamente amancebado procuré inmediatamente aplicar todos los oficios para separar a las mujeres con las que se asentaba estar en mal estado al fin de que se separase de su mala vida, y con efecto se consiguió que la una se pusiese en recogimiento, la otra se halla amonestada y de no enmendar su mala vida experimentará los rigores de un retiro ${ }^{25}$.

Siempre según la versión de don Basilio, a partir de estos incidentes el oidor habría buscado venganza, convirtiéndose en un enemigo peligroso no sólo para él, sino también para los propósitos de la Corona y de sus ministros; el mismo fiscal Pedro Rodríguez de Campomanes no habría escapado a las calumnias de Basaraz:

«Con lo que el citado ministro ha intensado su enemistad y subido tanto de punto que se me ha asegurado ha formado expedientes contra mi Dignidad y contra mis oficios, con otros conatos peligrosísimos sobre mi conservación y lo que más extraño ha sido en

23. A.H.N., Clero, Jesuitas, Leg. 239: Carta del Arzobispo de Manila Basilio Sancho al gobernador José Raón, Manila, 15 de octubre de 1769.

24. CUSHNER, N. P., Philippine Jesuits in exile, Roma, 1964. Diario del Padre de la Compañía Francisco Javier Puig, pp. 90-94.

25. A.H.N.. Clero, Jesuitas, leg. 239: Carta del Arzobispo de Manila Basilio Sancho al Rey, Manila, 1 de enero de 1770. 
mi estimación es el saber que ha propalado en diversos tiempos y delante de diversas personas que la expulsión de los jesuitas ha sido un puro invento de los hugonotes de Francia y que los impresos se habian forjado en casa de vuestro fiscal Don Pedro Rodriguez Campomanes». Y continúa: «este ministro es el que tiene la llave maestra a vuestro gobernador, para ser el arbitro y decisivo en todos los negocios que ocurren [...]. Suplico a V. M. separe inmediatamente a este ministro de esta Audiencia ${ }^{26}$.

En la misma carta enviada a Raón el 15 de octubre, el Ordinario no desaprovechaba la ocasión para recordar los aspectos más diabólicos de la Compañía de Jesús. Según su opinión, en Filipinas sucedía «que muchas de las mayores públicas desdichas que en ellas se refieren tuvieron su principio en los jesuitas que las motivaron». Y proseguía en la misma línea afirmando que «en otras partes del mundo, aunque han dominado los jesuitas y cometido atrocidades, ha habido al mismo tiempo muchos que los han conocido y tal vez llevados e impelidos de un santo celo han levantado contra ellos la voz, lo que pudo servirles de algún freno, pero en Filipinas ninguno ha habido para contenerlos, porque si no es los lastimados por ellos, nadie ha osado desplegar sus labios, y de las injusticias y escandalazos que han ocasionado, en vez de oprobios no han sacado del pueblo alucinado sino alabanzas, porque por una falsa piedad y arte diabólica llenaron de sombras desde los principios esta región y cono arbitros del pais de las tinieblas pudieron obrar lo malo con apariencias de bueno y cuando no cometian sino delitos eran venerados como unos santos» ${ }^{27}$.

El Arzobispo remarcaba que los libros cuestionados no eran injuriosos contra los jesuitas, sino más bien un mero análisis de la realidad, que debían conocer los súbditos de la Corona para que «todos lleguen alguna vez a entender los perjuicios y grandes daños que en todos tiempos y en todas partes han causado a la Iglesia y al Estado los jesuitas y el pernicioso enemigo que en ellos estaba España, criando y manteniendo en su seno para su perdición y ruina» ${ }^{28}$.

El asunto de los textos prohibidos coleó largo tiempo, siendo un tema lo suficientemente importante como para que se promulgara otro Edicto con fecha de 1 de noviembre de 1769 , donde se repetían los mismos argumentos que ya hemos visto en contra de los jesuitas y de su escuela, aunque revistiéndolos -como era natural- de un aire de mayor solemnidad. Además, se instruía a los fieles en la correcta doctrina y se les permitía leer los libros objeto de polémica:

"Usando de nuestra Potestad espicopal en edificación de las almas, por el presente declaramos poderse leer los referidos impresos con seguridad de conciencia y sin perjuicio de la sana doctrina, llevando en ello los santos fines ya expresados, y que bien lejos de lo contrario, es muy conveniente leerlos para desengañarse de muchos perjudiciales errores, en que la conciencia peligra y para venir en conocimiento de la santa verdad" ${ }^{29}$.

El documento habría sido otro instrumento de presión sobre el gobernador Raón, quien -una vez más- habría reaccionado con notoria pasividad a las quejas del Me-

26. Ibidem.

27. A.H.N., Clero, Jesuitas, leg. 239: Carta del Arzobispo de Manila Basilio Sancho al gobernador José Raón, Manila, 15 de octubre de 1769.

28. Ibidem.

29. A.H.N., Clero, Jesuitas, leg. 239: Arzobispo Basilio Sancho, Edicto, Manila, 1 de noviembre de 1769. 
trolitano acerca del comportamiento de Basaraz; pasividad que fue interpretada por Sancho como auténtica complacencia.

A diferencia de 1769 , en que las circunstancias pusieron a prueba frecuentemente el sistema nervioso de don Basilio, el balance de 1770 fue positivo para sus intenciones. El año empezó realmente bien. El grueso de los jesuitas -92 padres en totalabandonó por fin el archipiélago a finales de enero, repartido en los barcos «Santa Rosa de Lima» y «Venus». Un grupo más pequeño de 21 religiosos había sido expatriado pocos meses antes a bordo del «San Carlos», de manera que sólo quedaron en Filipinas una veintena entre enfermos y ancianos, incapaces de realizar un viaje de esa envergadura ${ }^{30}$.

En el otro frente de lucha, mantenido con el gobierno político de la provincia, también hubo buenas noticias para el Arzobispado. En julio desembarcaba en Manila el nuevo gobernador Simón de Anda y Salazar ${ }^{31}$, quien al poco de comenzar su mandato, en el mes de septiembre, decidió procesar a su antecesor en el cargo José Raón y a varios de sus ministros, entre ellos el propio Basaraz. Les acusó de haber operado con negligencia en el extrañamiento de los jesuitas y de buscar la ruina del anterior comisionado Manuel Galbán ${ }^{32}$. Sancho comenzaba a contemplar el paisaje filipino con mucha más claridad; sabía que los vientos soplaban ya en otra dirección:

«Con el arresto de las personas del Mariscal de Campo D. José Raón, de su escribano Juan Antonio Cossío y de los oidores D. Doningo Blas de Basaraz y D. Francisco Henriquez de Villacorta e inquisición de sus papeles y confianzas se evidenciará la conjuración contra el honrado y buen ministro, el difunto D. Manuel Galbán y que este miserable Arzobispo vive porque le quiere el cielo arrepentido de sus culpas» ${ }^{33}$.

Efectivamente, la llegada de Anda a las islas supuso para el Arzobispo un verdadero golpe de fortuna; sin haber movido pieza, eliminaba del tablero de juego a varios peligrosos adversarios y ganaba para su causa a una autoridad civil -ahora sí- totalmente en sintonía con su lenguaje antijesuita y regalista:

«El gobernador Raón recibió la Real Cédula de expatriación con la frescura y abandono que todas las demás»; sin embargo, "Simón de Anda trabaja día y noche con la mayor eficacia, celo y amor al Real Servicio y en los pocos meses que lleva de gobierno se han corregido varios desórdenes de esta República [...]. Yo le ayudo con oraciones y rogativas públicas que tengo intimadas en este Arzobispado" ${ }^{34}$.

A modo de conclusión podemos decir que el pontificado de Basilio Sancho en la diócesis de Manila (1767-1787) fue largo y extremadamente complicado. Tenaz y

30. LORENZO GARCÍA, Santiago, La expulsión de los jesuitas de la Provincia de Filipinas, op. cit.

31. CUSHNER, N. P., op. cit., p. 23.

32. A.G.S., Gracia y Justicia, leg. 691: «Apunte por mayor ajustado a los autos de los cargos que resulta a don José Raón, don Henríquez. de Villacorta, don Domingo Blas de Basaraz y don Juan Antonio Cossío, y parecer del gobemador de Filipinas sobre los de los dos primeros y el uiltimo»; y A.H.N., Estado, Procesos, Jesuitas, leg. 781: Proceso contra Domingo Blas de Basaraz, oidor de la Audiencia de Manila y juez comisionado para el extrañamiento de los jesuitas filipinos.

33. A.H.N., Clero, Jesuitas, leg. 239: Carta del Arzobispo de Manila Basilio Sancho al Conde de Aranda, Manila, 28 de diciembre de 1770.

34. Ibiden. 
convencido regalista, su principal empeño fue resucitar la aletargada jurisdicción episcopal, haciendo frente al crecido poder del clero regular isleño.

El análisis de las dificultades contra las que tropezó el Ordinario en sus primeros años ha sido el objeto de este estudio. Entre 1767 y 1770 el Metropolitano se enfrentó a los Provinciales de las distintas religiones con motivo de la visita pastoral, procuró acelerar al máximo las operaciones de expulsión de los jesuitas, hacia los que sentía gran aversión, y se opuso abiertamente al gobernador Raón y al comisionado Basaraz, a quienes acusó de negligentes en su labor política.

En el año 1770, el extrañamiento de la Compañía de Jesús en enero, la llegada a Manila en julio del nuevo gobernador Simón de Anda y Salazar -también inflexible regalista-, y la caída en desgracia de Raón y Basaraz en septiembre ofrecieron un breve, pero reparador respiro, al enérgico y firme Prelado. 